\title{
The challenges of novel interventions in complex aortic disease
}

\author{
Marissa Guo, MD, ${ }^{\mathrm{a}}$ Aroma Naeem, BA, ${ }^{\mathrm{b}}$ and Bo Yang, MD, PhD, ${ }^{\mathrm{b}}$ Ann Arbor, Mich
}

\footnotetext{
From the ${ }^{a}$ University of Michigan Medical School; and ${ }^{\mathrm{b}}$ Department of Cardiac Surgery, Michigan Medicine, Ann Arbor, Mich.

Dr Yang is supported by the NHLBI of NIH K08HL130614, R01HL141891, and R01HL151776, Phil Jenkins and Darlene \& Stephen J. Szatmari Funds.

Disclosures: The authors reported no conflicts of interest.

The Journal policy requires editors and reviewers to disclose conflicts of interest and to decline handling or reviewing manuscripts for which they may have a conflict of interest. The editors and reviewers of this article have no conflicts of interest.

Received for publication Sept 28, 2020; accepted for publication Sept 29, 2020; available ahead of print Oct 8, 2020.

Address for reprints: Bo Yang, MD, PhD, 5155 Frankel Cardiovascular Center, 1500 East Medical Center Dr, Ann Arbor, MI 48109 (E-mail: boya@med.umich.edu).

JTCVS Techniques 2020;4:57-60

2666-2507

Copyright (c) 2020 The Authors. Published by Elsevier Inc. on behalf of The American Association for Thoracic Surgery. This is an open access article under the CC BY-NC-ND license (http://creativecommons.org/licenses/bync-nd/4.0/).

https://doi.org/10.1016/j.xjtc.2020.09.037
}

Video clip is available online.

The branched single anastomosis frozen elephant trunk repair (B-SAFER) includes partial arch replacement, a stent graft placed at the zone 2 arch, and a small stent graft into the left subclavian artery through the arch stent graft. ${ }^{1}$ As B-SAFER remains a new technique, it is critical to monitor its efficacy and long-term outcomes in the management of descending thoracic aneurysms. We present 2 cases of aneurysmal expansion after B-SAFER, secondary to persistent perfusion of the false lumen, which necessitated open repair.

\section{CASE SUMMARIES}

\section{Case 1}

A 55-year-old man with Marfan syndrome and a history of acute type A dissection repair, followed by an acute on chronic type B dissection treated with B-SAFER (Table 1), presented to our facility with a rapidly expanding $7.5-\mathrm{cm}$ descending thoracic aortic aneurysm (dTAA). Using a left thoracotomy in the fourth and eighth intercostal spaces, we established cardiopulmonary bypass via subclavian artery perfusion and femoral vein return. Under hypothermic circulatory arrest (HCA) and antegrade cerebral perfusion through the left subclavian and lower body perfusion through femoral artery, a large intimal tear was identified at the branch point of the left subclavian artery. The frozen elephant trunk (FET) stent graft, which had been deployed over a guiding wire, was found to have been inserted into

\section{Case 2}

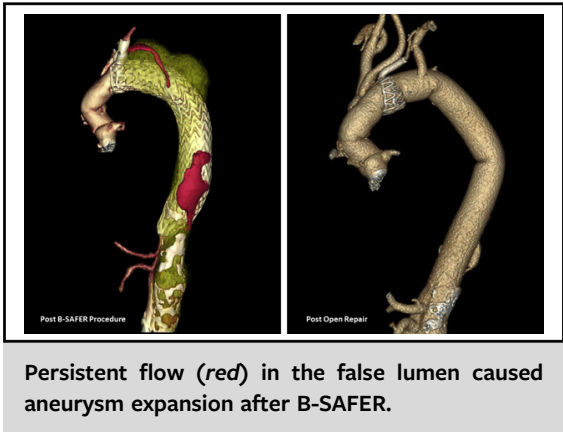

\section{CENTRAL MESSAGE \\ Although the B-SAFER proced- ure has its advantages, the stan- dard care remains open repair for $\mathrm{CTAA}$ or TAAA due to chronic aortic dissection.}

See Commentaries on pages 61 and 63 .

the false lumen. The stent graft and aorta were divided distal to the left vertebral artery and sewn to a 30-mm Dacron graft. HCA time was 30 minutes. The left subclavian artery was reimplanted via an 8-mm graft. The distal aorta was transected above the celiac artery and anastomosed to the Dacron graft with HCA after a 5-cm septectomy of the dissection flap. The left T11 intercostal artery was reimplanted via an 8-mm graft (Figures 1 and 2).

A 59-year-old woman presented with chronic type B dissection and 6.5-cm symptomatic thoracoabdominal aneurysm and stenosis of the celiac artery after B-SAFER (Table 1). Dissection of the proximal descending aorta and arch was challenging due to inflammatory changes and scarring from B-SAFER procedure. Under HCA, the aorta and FET were divided distal to the left subclavian artery. A patent false lumen at the proximal arch was identified as the cause of the proximal endoleak and obliterated using full-thickness 3-0 SH PROLENE suture. A 32-mm Dacron graft was then sewn to the distal arch, incorporating the stent graft. A pair of T11 intercostal arteries were reimplanted via $10-\mathrm{mm}$ grafts. The distal anastomosis was 
TABLE 1. History of cardiovascular interventions

\begin{tabular}{|c|c|c|}
\hline & Patient 1 (MFS) & Patient 2 \\
\hline $\begin{array}{l}\text { First } \\
\text { presentation }\end{array}$ & $\begin{array}{l}\text { 2000: Presented to an outside hospital with an acute type A } \\
\text { dissection. Underwent Bentall procedure with St Jude } \\
\text { mechanical composite valve graft and CABG. }\end{array}$ & $\begin{array}{l}\text { October 2013: Presented to the same outside hospital with an acute type B } \\
\text { aortic dissection extending from the left subclavian artery to the aortic } \\
\text { bifurcation. Treated medically. }\end{array}$ \\
\hline $\begin{array}{l}\text { B-SAFER } \\
\text { operation }\end{array}$ & $\begin{array}{l}\text { February 2018: Presented to the same hospital with an acute } \\
\text { on chronic type B dissection and dTAA measuring } \\
5.9 \mathrm{~cm} \text {. Underwent B-SAFER procedure with: } \\
\text { - Right vertebral-to-carotid artery transposition by } \\
\text { vascular surgery } \\
\text { - Redo ascending and zone } 2 \text { aortic arch replacement } \\
\text { - FET (C-TAG } 37 \mathrm{~mm} \times 10 \mathrm{~cm} \text { ) placed at zone } 2 \text { aortic } \\
\text { arch over a guidewire placed through femoral artery } \\
\text { - } 13 \text {-mm } \times 2.5 \text {-cm and } 6 \text {-mm } \times 5 \text {-cm VIABAHN stent } \\
\text { graft placement in the left subclavian and left vertebral } \\
\text { arteries } \\
\text { - Reimplantation of the left common carotid and } \\
\text { innominate arteries } \\
\text { March } 2018 \text { : Underwent completion TEVAR (C-TAG } \\
37 \mathrm{~mm} \times 20 \mathrm{~cm} \text { ) of the descending aorta to the level of } \\
\text { the celiac artery with balloon rupture of dissection flap } \\
\text { distally and placement of } 13 \text {-mm } \times 2.5 \text {-cm VIABAHN } \\
\text { stent graft in the LScA (Figure } 1 \text { ) }\end{array}$ & $\begin{array}{l}\text { November 2018: Presented to the same hospital with chronic type B } \\
\text { dissection and TAAA measuring } 5.2 \mathrm{~cm} \text {. Underwent B-SAFER procedure } \\
\text { with: } \\
\text { - Ascending aorta and hemiarch replacement } \\
\text { - FET (C-TAG } 37 \mathrm{~mm} \times 15 \mathrm{~cm} \text { ) placed from zone } 2 \text { aortic arch without } \\
\text { guidewire } \\
\text { - } 13 \mathrm{~mm} \times 2.5 \text {-cm VIABAHN stent graft placement in the left subclavian } \\
\text { artery (Figure } 3, C \text { ) }\end{array}$ \\
\hline $\begin{array}{l}\text { Open } \\
\quad \text { reoperation }\end{array}$ & $\begin{array}{l}\text { April 2019: Transferred to our facility with back pain and a } \\
\text { rapidly expanding dTAA measuring } 7.5 \mathrm{~cm} \text {. Underwent } \\
\text { urgent left-sided thoracotomy with: } \\
\text { - Left subclavian and femoral artery cannulation } \\
\text { - Aortic arch and descending thoracic aorta replacement } \\
\text { under HCA at } 18^{\circ} \mathrm{C} \text { (bladder) from zone } 2 \text { arch to celiac } \\
\text { artery with antegrade cerebral perfusion through LScA } \\
\text { - T11 intercostal artery reimplantation } \\
\text { - Cryoablation of T3-T9 intercostal nerves }\end{array}$ & $\begin{array}{l}\text { March 2019: Transferred to our facility with an expanding TAAA measuring } \\
6.5 \mathrm{~cm} \text {. Required pulmonary rehabilitation before surgery. } \\
\text { September 2019: Underwent a left-sided thoracoabdominal incision with: } \\
\text { - Left subclavian and femoral artery cannulation } \\
\text { - Aortic arch and thoracoabdominal aortic replacement under HCA from } \\
\text { zone } 3 \text { arch to superior mesenteric artery with antegrade cerebral } \\
\text { perfusion through LScA } \\
\text { - Celiac artery reimplantation } \\
\text { - T11 intercostal artery reimplantation } \\
\text { - Cryoablation of T3-T9 intercostal nerves }\end{array}$ \\
\hline
\end{tabular}

MFS, Marfan syndrome; $C A B G$, coronary artery bypass graft; $B$-SAFER, branched single anastomosis frozen elephant trunk repair; $d T A A$, descending thoracic aortic aneurysm; $F E T$, frozen elephant trunk; TEVAR, thoracic endovascular aortic repair; $L S C A$, left subclavian artery; TAAA, thoracoabdominal aortic aneurysm; $H C A$, hypothermic circulatory arrest.
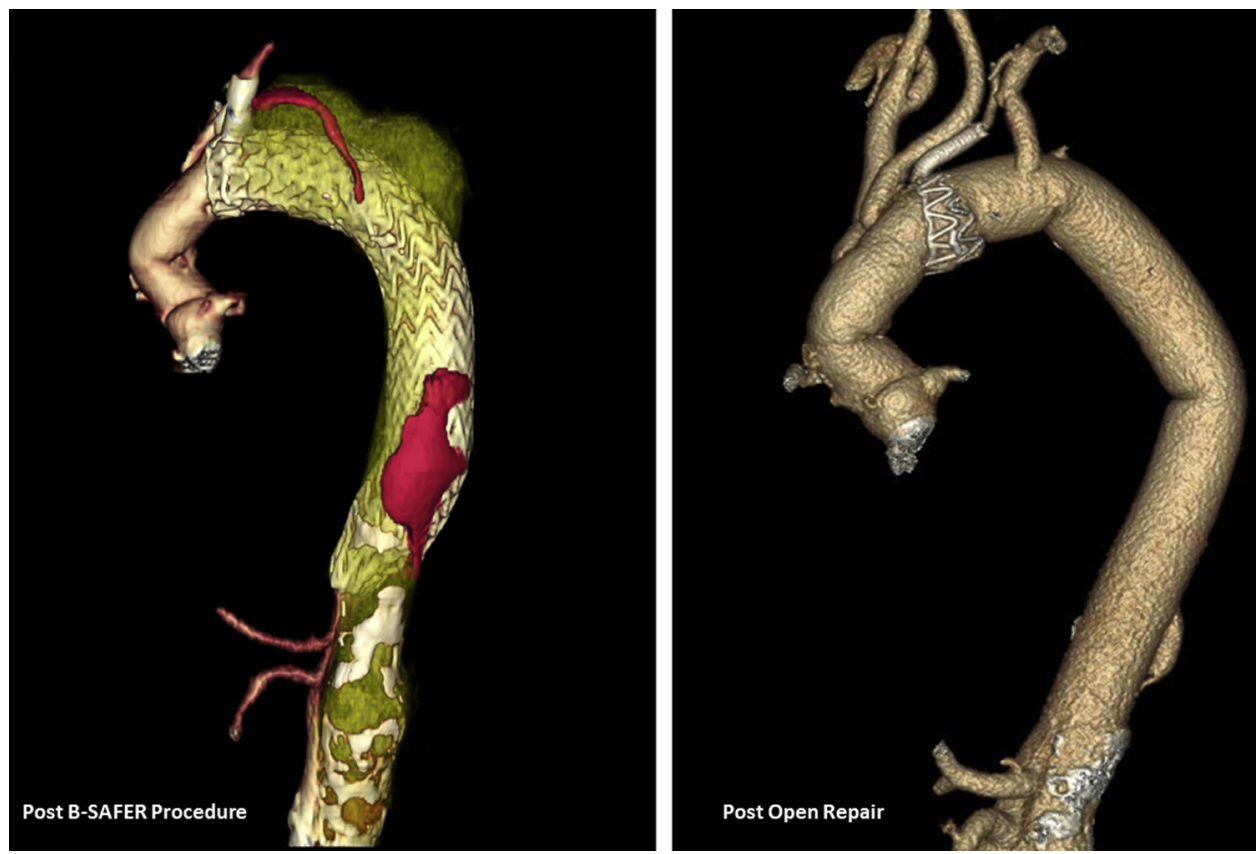

FIGURE 1. Persistent flow (red) in the false lumen caused aneurysm expansion after B-SAFER. 

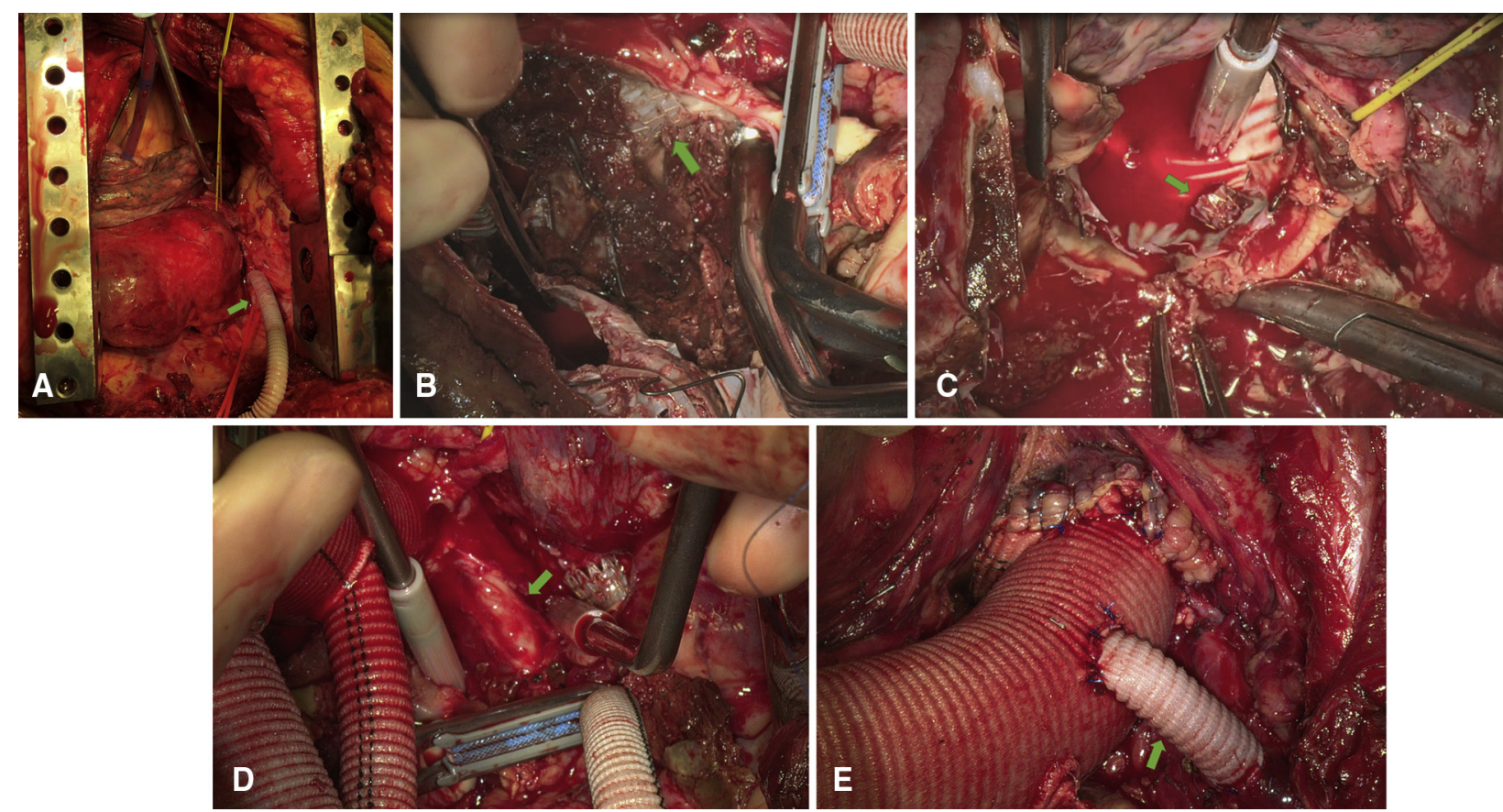

FIGURE 2. Intraoperative photos of open repair for patient 1 after B-SAFER procedure, who had Marfan syndrome with a continuous expansion of $7.5 \mathrm{~cm}$ descending thoracic aortic aneurysm. A, Left subclavian artery cannulation with an 8-mm Dacron graft. B, Incision into the aorta with visualization of the FET stent graft, left subclavian artery VIABAHN stent (green arrow), and large intimal tear. C, Intra-aortic view after proximal transection of the aorta distal to the stent graft in the left vertebral artery (green arrow). D, View of the left vertebral artery with VIABAHN stent (green arrow). E, Completed proximal anastomosis of the descending aortic Dacron graft to the aortic arch with reimplantation of the left subclavian artery via 8 -mm graft.

completed proximal to the superior mesenteric artery under HCA with reimplantation of celiac artery via a $10-\mathrm{mm}$ branch graft (Figure 3).

Postoperatively, both patients recovered well with no complications and minimal pain due to intercostal nerve ablation. ${ }^{2}$ Informed consent for patients included in this study has been waived by the University of Michigan Medical School institutional review board.

\section{COMMENT}

The B-SAFER procedure has been used in acute type A aortic dissection to simplify total arch and FET to obliterate the false lumen in the arch and proximal descending thoracic aorta and promote aortic remodeling and false lumen thrombosis. ${ }^{1,3}$ It has been expanded to dTAA from chronic aortic dissection. ${ }^{4}$ These 2 case presentations likely represent a continuous expansion of the proximal dTAA due to persistent blood flow into the false lumen proximally and distally after B-SAFER procedure. Case 1 had persistent proximal flow from the dissected left subclavian artery into the false lumen of the aorta, which was treated twice with stent grafts. Case 2 had a proximal leak from the false lumen of the remaining arch into the false lumen of the descending thoracic aorta secondary to incomplete closure of the false lumen at the anastomosis of the FET to dissected zone 2 arch. Both cases had persistent distal flow into the false lumen related to the stent graft's position in the true lumen of descending thoracic aorta; we also note that case 1 was on Coumadin for a mechanical aortic valve. In addition, case 1 was a patient with Marfan syndrome with dissection extended into the left subclavian artery and may not have been an ideal candidate for the B-SAFER procedure. At the presentation of a descending thoracic or thoracoabdominal aortic aneurysm, to complete a B-SAFER procedure necessitated a redo sternotomy and multiple procedures for patient 1 and replacement of the normal ascending aorta for patient 2 (Table 1). Alternatively, patient 1 could have had a reverse zone 2 arch replacement beveled to the previous ascending Dacron graft, and descending aorta replacement to the celiac artery. Patient 2 could have had reverse hemiarch replacement and thoracoabdominal aneurysm repair. Although the B-SAFER procedure has its advantages, the standard care remains open repair for dTAA or thoracoabdominal aortic aneurysm due to chronic aortic dissection, especially in patients with connective tissue disease (Video 1). 

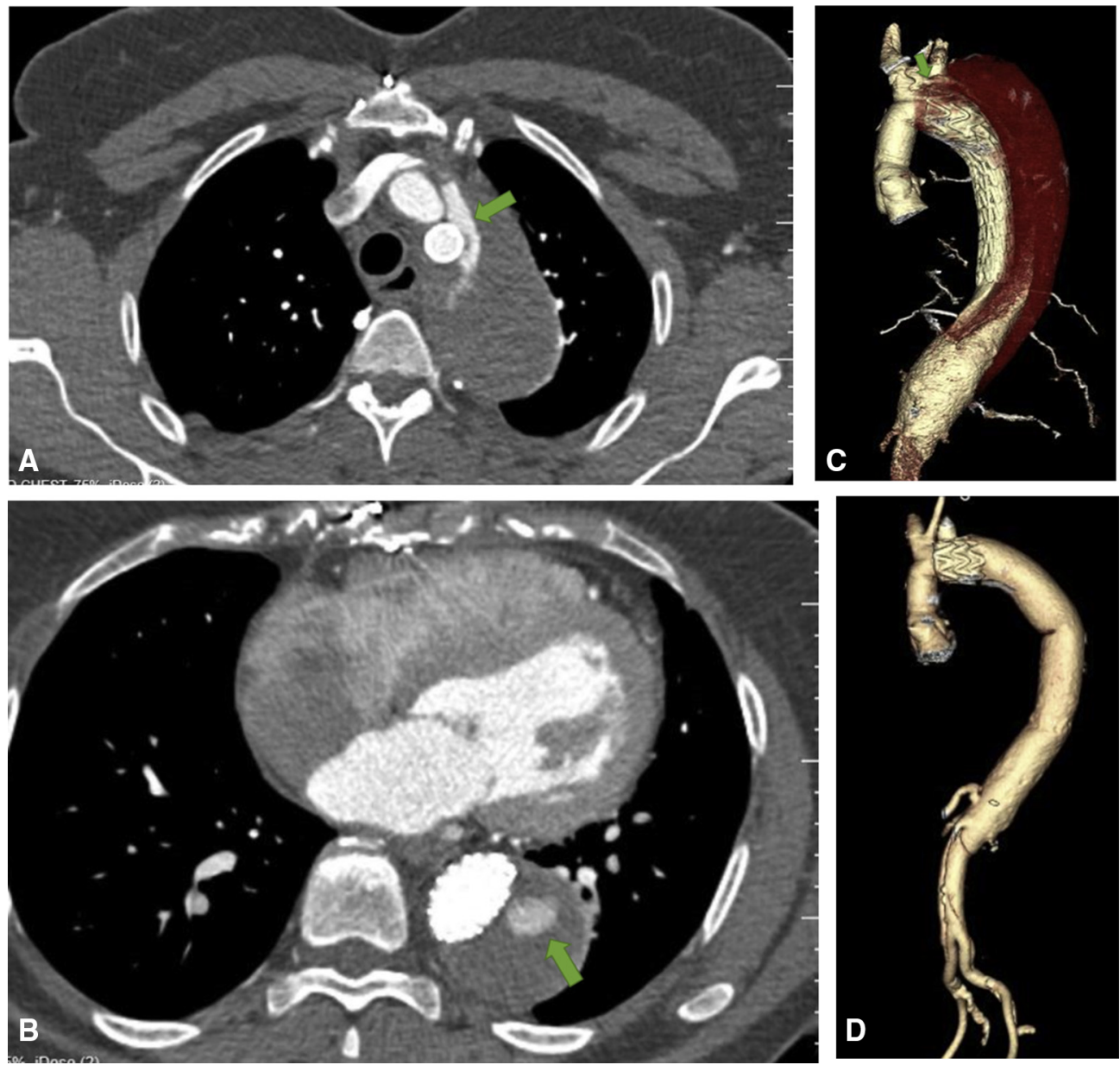

FIGURE 3. Case 2: Preoperative CT (March 2019) showing persistent proximal (A) and distal (B) blood flow (green arrows) into the false lumen. C, Threedimensional rending of CT (March 2019) depicting thoracoabdominal aneurysm measuring $6.5 \mathrm{~cm}$ in maximum diameter at the level of the left subclavian artery with persistent flow in the false lumen of the arch (green arrow) and descending thoracic aorta. D, 4-month postoperative CT (January 2020).

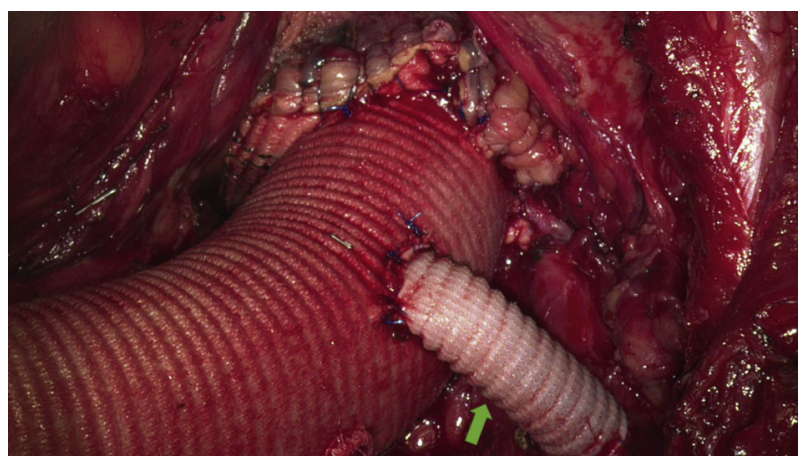

VIDEO 1. Discussion of potential causes of continuous expansion of descending thoracic aortic aneurysm after B-SAFER (branched single anastomosis frozen elephant trunk repair) procedure. Video available at: https://www.jtcvs.org/article/S2666-2507(20)30561-7/fulltext.

\section{References}

1. Roselli EE, Idrees JJ, Bakaeen FG, Tong MZ, Soltesz EG, Mick S, et al. Evolution of simplified frozen elephant trunk repair for acute DeBakey type I dissection: midterm outcomes. Ann Thorac Surg. 2018; 105:749-55.

2. Clemence J Jr, Malik A, Farhat L, Wu X, Kim KM, Patel H, et al. Cryoablation of intercostal nerves decreased narcotic usage after thoracic or thoracoabdominal aortic aneurysm repair. Semin Thorac Cardiovasc Surg. 2020;32:404-12.

3. Di Marco L, Pantaleo A, Leone A, Murana G, Di Bartolomeo R, Pacini D. The frozen elephant trunk technique: European Association for Cardio-Thoracic Surgery position and Bologna experience. Korean J Thorac Cardiovasc Surg. 2017; 50:1-7.

4. Roselli EE, Bakaeen FG, Johnston DR, Soltesz EG, Tong MZ. Role of the frozen elephant trunk procedure for chronic aortic dissection. Eur J Cardiothorac Surg. 2017;51:i35-9. 